\title{
Herd-level variables associated with premilking stimulation time in Michigan dairy herds
}

\author{
R. Moore-Foster, ${ }^{1}$ B. Norby, ${ }^{1}$ R. L. Schewe,${ }^{2}$ R. Thomson, ${ }^{3}$ P. C. Bartlett, ${ }^{1}$ and R. J. Erskine ${ }^{1 *}$ \\ ${ }^{1}$ Department of Large Animal Clinical Sciences, Michigan State University, East Lansing 48824 \\ 2Department of Sociology, Syracuse University, Syracuse, NY 13244 \\ ${ }^{3}$ Department of Animal Science, Michigan State University, East Lansing 48824
}

\section{ABSTRACT}

The objective of this study was to determine the herd-level variables that were associated with total stimulation time during the premilking routine in 64 Michigan dairy herds. The mean herd size was 452 cows (range $=59$ to 2,771 cows). For each herd, surveys were administered to producers to gather mastitis management practices and attitudes. Additionally, milking protocols were observed and milk flow dynamics were measured by use of digital vacuum recorders. Backward multivariate regression analysis was used to determine which of 47 herd-level milking and management variables were associated with mean total stimulation time. Mean total stimulation time was $14.2 \mathrm{~s}$ (range $=$ $2.4-40.8 \mathrm{~s}$ ) and was positively associated with increasing latency period (time interval between first stimulation and cluster attachment). Total stimulation time was negatively associated with greater herd size and number of visits to each cow in the premilking routine. In summary, increased stimulation time is more likely in herds that foster a lower sense of urgency of cow throughput during milking, as evidenced by a positive association with longer latency periods and fewer preparation visits per cow. Tactile stimulation is critical for efficient milk ejection; if inadequate, cows are at greater risk of delayed milk ejection and bimodal milk flow, which in turn has been associated with teat congestion and reduced milk flow. This study offers insight as to some of the herd factors that may be limiting adequate tactile stimulation.

Key words: premilking stimulation, milking protocols, employee management

Received April 18, 2018.

Accepted November 12, 2018.

*Corresponding author: erskine@msu.edu

\section{INTRODUCTION}

Premilking stimulation of the teats is necessary to induce a neural reflex arc that causes oxytocin release from the pituitary gland into the circulation, which in turn activates the myoepithelial cells to force milk ejection (Bruckmaier, 2005). Weiss and Bruckmaier (2005) recommended that the duration of prestimulation before milking should be at least $20 \mathrm{~s}$ for well-filled udders, although those authors did not include a latency period (time interval between first stimulation and cluster attachment). In a more recent study, stimulation of at least $15 \mathrm{~s}$ before milking was ideal for optimal milk letdown if a latency period of at least $45 \mathrm{~s}$ was included (Kaskous and Bruckmaier, 2011). However, with low udder filling, longer prestimulation periods of $90 \mathrm{~s}$ can be helpful (Kaskous and Bruckmaier, 2011), which may not be practical in some parlor environments. Because of the short plasma half-life of oxytocin, no more than 2 min should pass between tactile stimulation and milking unit attachment (Bruckmaier, 2013).

As greater myoepithelial contraction is needed to eject milk out of incompletely filled as compared with filled alveoli (Bruckmaier and Wellnitz, 2008), udder stimulation is more important for late-lactation cows compared with recently calved cows (Sandrucci et al., 2007). Additionally, increased risk of bimodal milk flow has been associated with inadequate premilking stimulation (Sandrucci et al., 2007; Bruckmaier, 2013; Watters et al., 2015), although other researchers have suggested that stimulation by stripping before milking did not affect milk flow or yield (Wagner and Ruegg, 2002).

Recently, we completed a study that found that inadequate premilking stimulation and increasing herd size were the most important variables associated with delayed milk ejection and bimodal milk flow (MooreFoster et al., 2019). However, delayed milk ejection can occur without bimodal milk flow (e.g., with frequent milking) because the amount of cisternal milk is very low. Thus, to further elucidate the factors related to milking efficiency, the objective of the current study 
was to determine the herd-level variables, including labor culture, that were associated with the duration of premilking stimulation in 64 Michigan dairy herds.

\section{MATERIALS AND METHODS}

\section{Dairy Farm Selection}

This study was part of a larger project in which 124 dairy herds in Florida, Michigan, and Pennsylvania participated in a 15-mo trial to develop an evaluation to assess mastitis and antimicrobial drug use. The 64 Michigan dairy herds that participated in the larger study were visited by the investigators twice between January 2016 and May 2017. Enrolled herds had >70 cows; herds that milked with automated milking systems were excluded.

\section{Herd Profile and Management Culture}

During the initial herd visit, project investigators explained the study design and collected a herd profile to record milking times and groups, type of milking facility, housing, employee structure, and other general information from surveys and observation. To capture information relative to the management culture, we interviewed dairy producers or managers with a survey of their mastitis control practices and attitudes. The survey instrument and responses that were obtained from the larger project, of which farms in this study were included, are available in the appendix of a previous publication (Schewe et al., 2015). The questions included from this survey for this study are presented in Table 1. All survey information was collected following approval and within the guidelines of the Institutional Review Board of Michigan State University. Later, the investigators returned for a second visit to conduct a milk quality evaluation that included (1) milking behaviors and proficiency, (2) milking systems, (3) cow environment, (4) monitoring and therapy of infected cows, and (5) farm management culture. Further details of the evaluation have been previously reported (Moore-Foster et al., 2019).

\section{Parlor Behaviors and Analysis}

Milking protocols were observed to determine the milking routine, the time interval between each preparation step, the time interval between first stimulation and cluster attachment (latency period), and time spent stimulating the teats. We defined the total duration of teat stimulation (TS) as the cumulative time spent applying tactile stimulation to the teats, exclusive of the time between periods of tactile stimulation. For our analysis, we included wiping, drying, and stripping of the teats, or use of automated teat brush equipment, as contributing to tactile stimulation, but not spraying or dipping of teats with a germicide. Additionally, the first touch of the routine was considered to only begin with a behavior that involved tactile stimulation.

We recorded the elapsed time for each behavior of the entire premilking routine by either taking videos with the camera app in a cell phone $(62 / 64$ herds) for later review, or with the aid of a stopwatch and split time function in a cell phone $(2 / 64$ herds). The time that each premilking behavior (e.g., forestripping teats) was initiated and completed was recorded to determine the actual elapsed time spent on each behavior. In some cases, 2 behaviors were completed during 1 pass (e.g., drying teats and attaching clusters), but each behavior was still recorded separately. We also recorded the total elapsed time for each pass, which may have included behaviors other than directly prepping the udder, such as gathering towels, and total elapsed time for the sum of all passes for each cow. Additionally, we recorded the latency period for each cow. A minimum of 4 milking strings were recorded during milking preparation in parlors and the mean time for all the observed cows in each herd was calculated for each behavior of the premilking routine. In platform or tiestall milking operations, stimulation and latency periods were recorded for at least 4 cows per cluster. When more than 1 person was milking, milking behaviors were observed for a minimum of 2 milking strings for each person.

\section{Parlor Ergonomics}

Measures of parlor ergonomics, such as light availability, duration of a milking shift, the median linear distance traveled by employees while performing milking tasks, and the availability of breaks during the shift, were determined as previously described (Moore-Foster et al., 2019).

\section{Statistical Analysis}

Dependent Variable. The dependent variable for this study was mean TS during the premilking routine in each herd, as determined by observation by the researchers. Thus, for each cow in a herd, TS was calculated as the sum of the elapsed time for the behaviors that provided tactile stimulation (stripping, drying, and so on) and then the mean for each herd was derived from all observed cows within the herd. The data were entered into Microsoft Excel (Microsoft Corp., Redmond, WA) for data management and imported into SAS (ver. 9.4; SAS Institute Inc., Cary, NC) for descriptive and statistical analyses. 
Table 1. Questions included in a survey of dairy producers or managers from 64 Michigan dairy herds

\begin{tabular}{|c|c|}
\hline Question & Question entry \\
\hline How often do you train (or milk with) employees regarding milking protocols? & $\begin{array}{l}0=\text { Never } \\
1=\text { Only when hired } \\
2=\text { Once } / y r \\
3=\text { Every } 3 \text { mo } \\
4=1+/ \text { month } \\
5=\mathrm{N} / \mathrm{A}^{1} \\
9=\mathrm{No} \text { answer }\end{array}$ \\
\hline In your opinion, what percentage of milkers follow milking protocols? & $\begin{array}{l}1=\text { Not many }(25 \% \text { or less }) \\
2=\text { Some }(26-50 \%) \\
3=\text { Most }(51-75 \%) \\
4=\text { Almost all of them }(76-100 \%) \\
9=\text { No answer }\end{array}$ \\
\hline $\begin{array}{l}\text { What percentage of milkers tell management when there is a problem } \\
\text { or broken equipment? }\end{array}$ & $\begin{array}{l}1=\text { Not many }(25 \% \text { or less }) \\
2=\text { Some }(26-50 \%) \\
3=\text { Most }(51-75 \%) \\
4=\text { Almost all of them } \\
9=\text { No answer }\end{array}$ \\
\hline What percentage of milkers offer feedback or ideas on how to improve the operation? & $\begin{array}{l}1=\text { Not many }(25 \% \text { or less }) \\
2=\text { Some }(26-50 \%) \\
3=\text { Most }(51-75 \%) \\
4=\text { Almost all of them }(76-100 \%) \\
9=\text { No answer }\end{array}$ \\
\hline How important is recruiting/retaining good employees? & $\begin{array}{l}1=\text { Very important } \\
2=\text { Important } \\
3=\text { Not important } \\
4=\text { Not at all important } \\
9=\text { No answer }\end{array}$ \\
\hline How important is improving parlor turnover rate $($ cows $/ \mathrm{h}) ?$ & $\begin{array}{l}1=\text { Very important } \\
2=\text { Important } \\
3=\text { Not important } \\
4=\text { Not at all important } \\
9=\text { No answer }\end{array}$ \\
\hline How important is changing your communication with your employees? & $\begin{array}{l}1=\text { Very important } \\
2=\text { Important } \\
3=\text { Not important } \\
4=\text { Not at all important } \\
9=\text { No answer }\end{array}$ \\
\hline
\end{tabular}

${ }^{1} \mathrm{~N} / \mathrm{A}=$ not applicable.

Independent Variables. The independent variables were divided into 3 categories: (1) management culture and human resources, (2) employee behaviors, and (3) parlor factors. Management culture and human resource variables include milking operator turnover rates (defined as number of operators hired per year divided by number of positions available, reported by the producer), as well as survey questions that include frequency of employee training, manager attitudes about parlor turnover rates, and how often managers communicate with employees on personal matters. In addition, we recorded herd compensation, including pay rate and, if applicable, other benefits. Employee behaviors included latency period, estimated distance traveled in the parlor per shift, number of stalls per milking preparation pass, and parlor flow rates (described as cows milked per hour, cows milked per employee per hour, and milking strings per hour). Parlor factors include rail height, light intensity, how many times cows were milked per day, if $95 \%$ of liners were properly aligned (yes $=1$, no $=0$ ), and if $95 \%$ of air vents on the cluster were unobstructed (yes $=1$, no $=0$ ).

Scale Factor Analysis. Initially a frequency distribution was set up for each independent variable in our model and normality was checked. We performed principal component factor analysis to determine if it was possible and appropriate to combine independent variables into composite scales or factors relative to management attitudes and parlor flow variables; however, $\alpha$ and Eigenvalues were not significant for any scales (Eigenvalue $>1$ and Cronbach's $\alpha>0.7$ ).

Bivariate Analysis. Right-skewed continuous-level variables were log-transformed before the bivariate analysis so that normality was attained. To decide which independent variables should be included in the model for multivariate analysis, associations between TS and explanatory continuous variables were investigated using Pearson's product moment correlation coefficient. For binary (nominal) variables, the dependent variables were compared with the independent variables using an 
adjusted Wald test for the significance of the relationship. Any variables with an initial cutoff of $P<0.20$ ( 2 tails) were considered eligible for inclusion in the multivariable model.

Multiple Linear Regression. Using multiple regression and the type-III $F$-test, an automated backward-stepwise elimination analysis was used to build the final multivariable model until only significant covariates $(P<0.05)$ were retained. To test for potential multicollinearity, interactions were also checked; however, no significant relationships were found. Herd size was also analyzed as a confounder and the change to the coefficients and coefficient of determination values were minimal for the explanatory variables of (1) latency period and (2) number of visits during the prep procedure; however, the coefficient of determination was greater than $10 \%$ for shift length. Thus, herd size was considered as a confounder in the model. The residual distribution was assessed visually for normality and to ensure that the variance of the variables were homogeneous.

\section{RESULTS}

The mean herd size was $451($ median $=294)$ milking cows, ranging from 59 to 2,771 cows (Table 2). Cows were milked with automatic cluster detachers in $94 \%$ $(61 / 64)$ of herds, and $62 / 64$ herds $(97 \%)$ reported using hired labor.

Descriptive data for both the outcome variable (TS) and explanatory variables are also listed in Table 2 . Mean TS for all herds was $14.2 \mathrm{~s}$ and a distribution of TS for the herds is presented in Figure 1. Based on the bivariate analysis, 10 variables were significantly and negatively related to TS in 3 categories: (1) management culture and human resources [herd size, hours of operation per day for the milking system, operator shift length (includes time spent milking and additional chores, if shift length spanned multiple milking shifts then break length was deducted), break length for operators during their shift, and number of visits to each cow in the preparation routine], (2) employee behaviors (number of cows per operator hour prepped in the parlor), and (3) parlor factors (number of milking units, the number of cows milked per hour, rail height, and illumination in the milking workspace). Conversely, the employee behavior of mean latency period was positively associated with TS.

Using backward stepwise regression, our multivariate regression found the number of passes in the premilking routine and herd size (natural log) to be negatively associated with mean TS (Table 3). Mean TS was positively associated with mean latency period of the premilking routine. Because of herd size being retained in the final model, we performed a 2 -sample $t$-test to compare means, stratified by herd size, to better understand the effect of herd size on TS. Mean TS for herds with $<300$ cows $(16.8 \mathrm{~s})$ was greater than herds with $\geq 300$ cows $(8.7 \mathrm{~s} ; P<0.05)$. The cutoff point for herd size selected for large ( $\geq 300$ cows) and small $(<300$ cows $)$ dairies was based on the criterion used for the umbrella project of the present study (Schewe et al., 2015), which reflected the intent to identify herds that were likely to hire nonfamily labor (larger herds) as compared with herds that were more likely to rely mostly on family labor (smaller herds).

\section{DISCUSSION}

Weiss and Bruckmaier (2005) reported that the optimal duration of prestimulation to reduce delayed milk ejection was $90 \mathrm{~s}$ in udders containing small amounts of milk, but only $20 \mathrm{~s}$ in well-filled udders; however, this was measured with continuous stimulation without a latency period. In mid-lactation cows, stimulation of at least $15 \mathrm{~s}$ before milking is ideal for optimal milk letdown if a latency period of at least $45 \mathrm{~s}$ is included (Kaskous and Bruckmaier, 2011). However, the duration of both stimulation and latency period may not be as critical to promote efficient milk ejection in cows that have greater udder filling at milking, such as cows in early lactation compared with cows in later lactation (Kaskous and Bruckmaier, 2011). These guidelines were similar (mean TS $=14.2 \mathrm{~s}$ ) or exceeded by (mean latency period $=103 \mathrm{~s}$ ) the observed behaviors in our study. In a review, Bruckmaier (2005) suggested that latency periods $>2$ min have a negative effect on milk flow. Thus, adequate stimulation with a latency period is required to optimize milk ejection, but the latency period should not be too long to prevent a decline of oxytocin to baseline before cluster attachment.

In a Wisconsin study, stripping as part of the premilking routine did not increase milk flow or yield in cows compared with cows that were not stripped (Wagner and Ruegg, 2002). However, both stripped and nonstripped cows were vigorously dried for 10 to 15 $\mathrm{s}$ just before cluster attachment (Wagner and Ruegg, 2002). In our study, only $54 \%$ of herds stimulated teats $>10$ s during the initial tactile visit (germicide application excluded). This indicates that many herds might have an opportunity to increase milking efficiency by increasing the proportion of stimulation earlier in the routine to optimize latency period intervals.

Our results determined that TS decreased as the number of passes in the premilking routine and herd size increase within herds; conversely, TS increased as the latency period of the routine increased. It seems paradoxical that fewer passes in a milking routine but 
Table 2. Descriptive data of independent variables from 64 Michigan dairy herds ${ }^{1}$

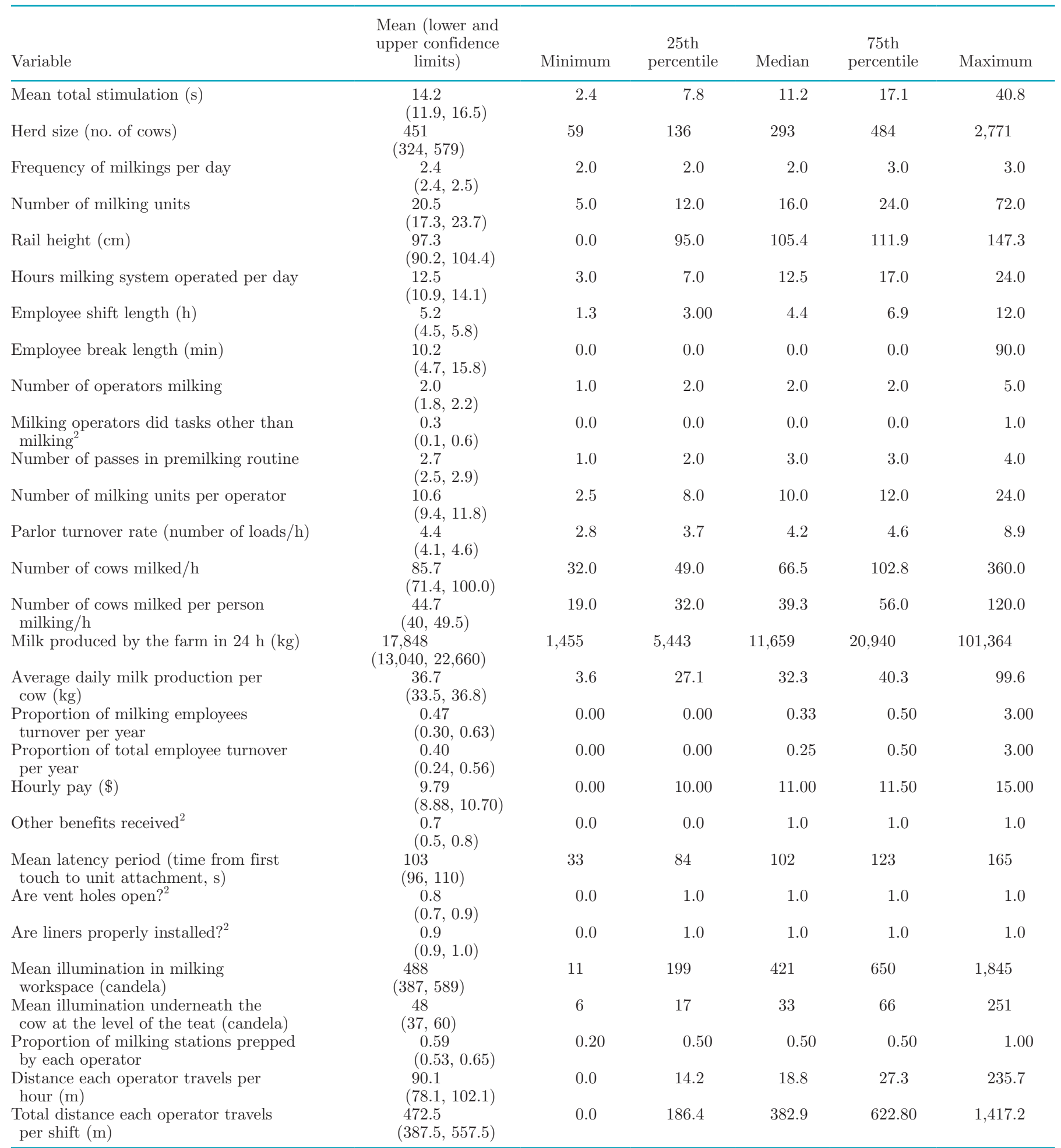

${ }^{1}$ Many of the variables in this table were previously described by Moore-Foster et al. (2019).

${ }^{2} 1=$ yes; $0=$ no.

a longer latency period are both associated with greater TS; however, this may suggest that herds with greater TS have a routine that results in more stripping and wiping during each visit per cow and might also increase the latency period. In addition, the efficiency of the milking routine to induce oxytocin, and therefore 


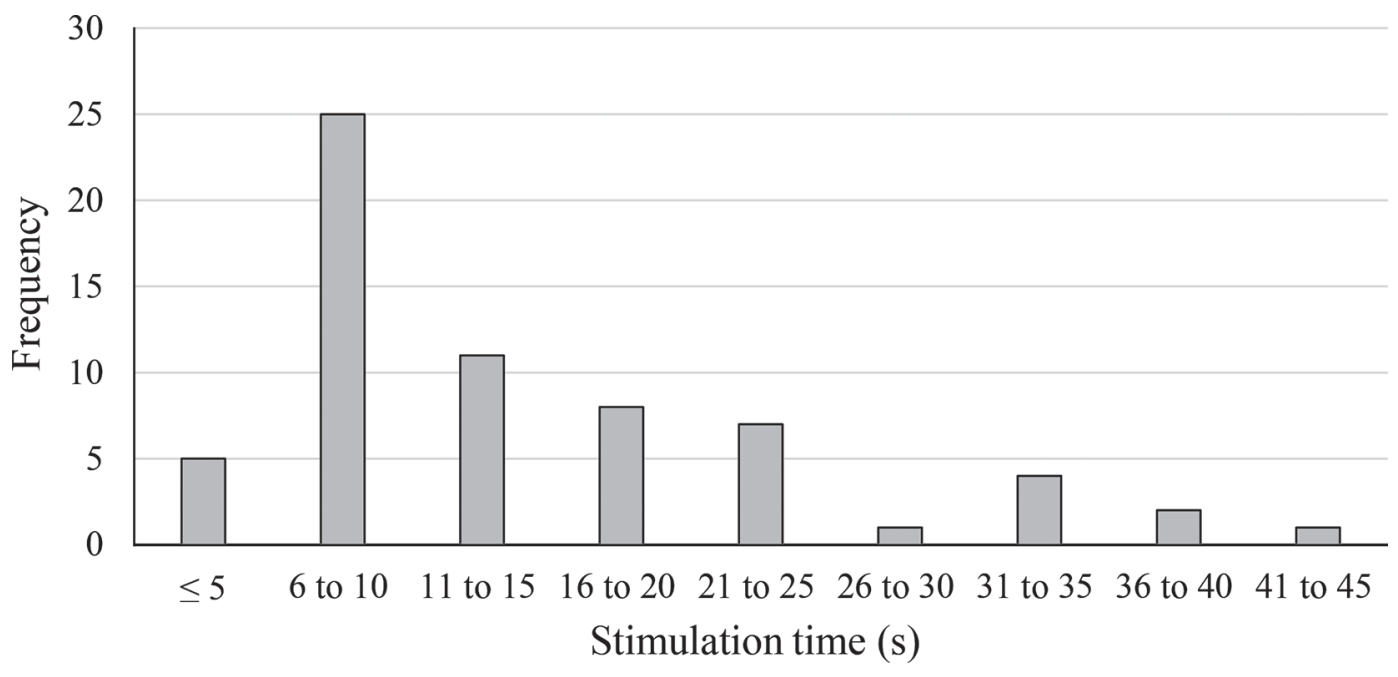

Figure 1. Histogram of mean total stimulation time (s) during the premilking routine for 64 Michigan dairy herds.

reduce delayed milk ejection, may be better in herds that spend more time stimulating teats and less time traveling between cows.

Herd size was determined to be a confounder in this analysis. Thus, the effect on TS from several explanatory variables that were found to be strongly correlated on bivariate analysis, such as shift length, the number of cows milked per hour, and the number of milking units per operator, were likely masked due to herd size.

Collectively, our regression analysis suggests that a milking routine that promotes milking efficiency as compared with parlor efficiency results in better TS of the teats and, as found in a previous report (Moore-Foster et al., 2019), less delayed milk ejection. For example, operators in smaller herds, who milk cows in shorter time shifts, are under less pressure to finish milking before the next milking shift begins, or do not need to make as many visits to each cow before cluster attachment, may be more willing to strip and dry teats more thoroughly. Previously, Sandrucci et al. (2007) found that less time is spent on proper teat stimulation as farm size increases, thus reducing time for udder preparation and increasing bimodality. Our study agreed with these results, as mean TS in herds with $<300$ cows was nearly twice that of herds with $\geq 300$ cows. In contrast, the USDA NAHMS (2014) Dairy survey cited $86 \%$ of herds with $\geq 500$ cows forestripped during their milking routine as opposed to $66 \%$ in herds with $<500$ cows. However, dairy producers self-reported this qualitative information and TS for each herd of the entire milking routine was not measured. In a survey of nearly 1,200 herds across Canada (Belage et al., 2017), 82 and $84 \%$ of herds forestripped and dried udders before milking, respectively. No difference in these milking practices relative to herd size was found; however, the categories for herd size were $<37,37$ to 80 , and $>80$ cows and the third quartile of herds had 80 cows. Thus, the need for hired labor was likely to be very different between the Canadian study and ours.

One of the limitations of our study was that the number of cow-observations within each herd depended on herd size, milking shift length, and cow throughput while milking. Additionally, we observed at least 4 milking strings within each herd, but the proportion of cow-observations relative to herd size was not consistent, as the number of cows within a milking string varied considerably; we did note an overall trend to observe more cows in larger herds. We attempted to attain a representative sample within each herd. In smaller herds, (milking shifts less than $4 \mathrm{~h}$ ) we were present throughout the entire milking, but in larger herds it was difficult to evaluate all employees and

Table 3. Final linear model for associations between mean total stimulation time during the premilking routine and herd-level variables in 64 Michigan dairies (herd size included)

\begin{tabular}{lcccc}
\hline Parameter & Estimate & $\mathrm{SE}$ & $P$-value & $\mathrm{R}^{2}$ \\
\hline Intercept & 4.43 & 0.56 & $<0.0001$ & 0.58 \\
Herd size (natural log) & -0.31 & 0.11 & 0.009 & \\
Mean latency period (s) & 0.008 & 0.002 & $<0.001$ & \\
Number of passes & -0.30 & 0.08 & $<0.001$ & \\
\hline
\end{tabular}


all milking groups of cows across all shifts. Thus, in herds with short intervals between milking shifts, we recorded milking events in portions of 2 consecutive shifts to gain a wider perspective of milking behaviors. Additionally, we decided to include as our dependent variable only the actual time of tactile stimulation and not the total time of the premilking routine. A future analysis that would include herds from other states in our larger umbrella study, but exclude smaller herds (especially those that do not employ nonfamily labor), might better discriminate the explanatory variables for teat stimulation without the oversized importance of herd size as observed in this study.

Anecdotally, milking routines were often disrupted because of washing clusters or parlor platforms, acquiring clean towels from laundry bins, gathering cows from holding pens, reattaching or adjusting units on cows throughout the parlor, and filling teat dip applicators. Thus, we found no assurance that our observed mean TS for each herd was consistently practiced for every milking string of cows. Likewise, as previously suggested by Wagner and Ruegg (2002), it is difficult to know the contribution of premilking germicide application on milk ejection as opposed to true tactile stimulation. However, all of our herds applied a premilking germicide by either spraying, dipping, or foaming. Thus, due to the universal nature of this procedure, our study focused on tactile stimulation. To this end, we found considerable variation (2-41 s) between herds as opposed to a higher degree of consistency with germicide application and latency periods.

Finally, we attempted to capture ergonomic factors that might affect the operator's ability to adequately stimulate teats (e.g., was the height of the work platform an impediment for the operator to effectively reach the udder for preparation). Unfortunately, we did not collect data relative to employee height, nor did we account for the variety of behaviors that might affect this potential problem, such as the presence of steps or the willingness of the employee to step on the milk pipeline. Thus, ergonomic factors that may play a role in tactile stimulation were not completely accounted for in our study.

\section{CONCLUSIONS}

Smaller herd size, fewer visits to each cow in the premilking routine, and greater latency periods are associated with increasing TS in dairy herds. Variables such as greater shift length and the number of cows milked per hour may also affect TS, but are confounded by herd size. Thus, a milking culture that emphasizes milking efficiency rather than parlor efficiency may lead to better premilking stimulation. With increasing consolidation of the dairy industry, milking routines should be evaluated to determine if adequate TS is practiced to help maintain teat and udder health.

\section{ACKNOWLEDGMENTS}

This project was supported by Agriculture and Food Research Initiative Competitive Grant no. 2013-6800420439 from the USDA National Institute of Food and Agriculture (Washington, DC). The authors also thank Trevor Walling, Caitlin McNichols, Leah Girard, and Ellen Launstein (Department of Large Animal Clinical Sciences, Michigan State University, East Lansing) for technical assistance, and participating dairy producers and their employees.

\section{REFERENCES}

Belage, E., S. Dufour, C. Bauman, A. Jones-Bitton, and D. F. Kelton. 2017. The Canadian National Dairy Study 2015-Adoption of milking practices in Canadian dairy herds. J. Dairy Sci. 100:38393849 .

Bruckmaier, R. M. 2005. Normal and disturbed milk ejection in dairy cows. Domest. Anim. Endocrinol. 29:268-273.

Bruckmaier, R. M. 2013. Oxytocin from the pituitary or from the syringe: Importance and Consequences for milking machine in dairy cows. Pages $4-11$ in Proc. NMC Annual Meeting. National Mastitis Council, New Prague, MN.

Bruckmaier, R. M., and O. Wellnitz. 2008. Induction of milk ejection and milk removal in different production systems. J. Anim. Sci. $86: 15-20$.

Kaskous, S., and R. M. Bruckmaier. 2011. Best combination of prestimulation and latency period duration before cluster attachment for efficient oxytocin release and milk ejection in cows with low to high udder-filling levels. J. Dairy Res. 78:97-104.

Moore-Foster, R., B. Norby, R. L. Schewe, R. Thomson, P. C. Bartlett, and R. J. Erskine. 2019. Herd-level variables associated with delayed milk ejection in Michigan dairy herds. J. Dairy Sci. 102:696705. https://doi.org/10.3168/jds.2018-14561.

Sandrucci, A., A. Tamburini, L. Bava, and M. Zucali. 2007. Factors affecting milk flow traits in dairy cows: Results of a field study. J. Dairy Sci. 90:1159-1167.

Schewe, R. L., J. Kayitsinga, G. A. Contreras, C. Odom, C. A. Coats, P. Durst, E. P. Hovingh, R. O. Martinez, R. Mobley, S. Moore, and R. J. Erskine. 2015. Herd management and social variables associated with bulk tank somatic cell counts in dairy herds in the eastern United States. J. Dairy Sci. 98:7650-7665.

USDA NAHMS. 2014. Dairy 2014 milk quality, milking procedures and mastitis on U.S. dairies, 2014. Fort Collins, CO. Accessed Mar. 5, 2018. https://www.aphis.usda.gov/aphis/ourfocus/animalhealth/ monitoring-and-surveillance/nahms/nahms_dairy_studies/

Wagner, A. M., and P. L. Ruegg. 2002. The effect of manual forestripping on milking performance of Holstein dairy cows. J. Dairy Sci. 85:804-809.

Watters, R. D., R. M. Bruckmaier, H. M. Crawford, N. Schuring, Y. H. Schukken, and D. M. Galton. 2015. The effect of manual and mechanical stimulation on oxytocin release and milking characteristics in Holstein cows milked 3 times daily. J. Dairy Sci. 98:1721-1729

Weiss, D., and R. M. Bruckmaier. 2005. Optimization of individual prestimulation in dairy cows. J. Dairy Sci. 88:137-147. 